\title{
Retraction Note to: Investigation on Spark Erosion Machining Induced Surface Integrity of Super-Alloys
}

\author{
Neeraj Sharma and Kamal Kumar
}

\section{Retraction Note to:}

Chapter "Investigation on Spark Erosion Machining Induced Surface Integrity of Super-Alloys" in: K. Gupta (ed.), Materials Forming, Machining and Post Processing, Materials Forming, Machining and Tribology, https://doi.org/10.1007/978-3-030-18854-2_6

The Editor has retracted this chapter [1] because a number of the figures and tables appear to have been published previously by the authors. Figures 2, 3 and 11-14 overlap with Figures 1, 2 and 6a-d of [2]. Table 1 appears to partly overlap with Table 1 of [2]. Table 2 appears to overlap with Table 2 of [2]. Figures 5 and 6 appear to overlap partly with Figures 2 and 3 of [2]. Figures 7, 8, 10a and 10b appear to overlap with Figures 5, 6, 9a and 9c of [2]. Figure 9 appears to partly overlap with Figure 8 of [2]. Both authors agree with this retraction.

[1] Sharma N., Kumar K. (2020) Investigation on Spark Erosion Machining Induced Surface Integrity of Super-Alloys. In: Gupta K. (ed.) Materials Forming, Machining and Post Processing. Materials Forming, Machining and Tribology. Springer, Cham

[2] Kumar, V., Kumar, V \& Jangra, K. (2015). An experimental investigation and statistical modelling for trim cutting operation in WEDM of Nimonic-90. International Journal of Industrial Engineering Computations, 6(3), 351-364.

[3] Kamal Kumar Jangra, Vinod Kumar, Vikas Kumar, An Experimental and Comparative Study on Rough and Trim Cutting Operation in WEDM of Hard to Machine Materials, Procedia Materials Science, Volume 5, 2014, Pages 16031612, https://doi.org/10.1016/j.mspro.2014.07.348. 